\title{
Submitted: \\ 25.06.2018 \\ Accepted: \\ 02.10.2018 \\ Serum TSH level in obese children and its correlations with atherogenic lipid indicators and carotid intima media thickness
}

Published:

31.12 .2018

Keywords

TSH,

carotid IMT, obesity, children

\author{
Małgorzata Rumińska1', Ewelina Witkowska-Sędek¹, Anna Majcher ${ }^{1}$, \\ Michał Brzewski², Monika Krawczyk¹, Beata Pyrżak ${ }^{1}$
}

${ }^{1}$ Department of Pediatrics and Endocrinology, Medical University of Warsaw, Poland

${ }^{2}$ Department of Pediatric Radiology, Medical University of Warsaw, Poland

Correspondence: Małgorzata Rumińska, Żwirki i Wigury Street 63A, 02-091 Warsaw, Poland; tel./ fax: +48 2231797 12, e-mail:mruminska@wum.edu.pl

DOI: $10.15557 / J o U .2018 .0043$

\begin{abstract}
Objective: Moderately elevated level of thyroid-stimulating hormone accompanied by normal serum concentrations of free thyroxine, suggesting subclinical hypothyroidism, is the most common hormonal abnormality in obese children. Controversy remains, whether a thyroid dysfunction related to obesity has an influence on the cardiovascular risk factors. The aim of the study was to assess correlation between thyroid-stimulating hormone and free thyroxine and chosen atherogenic lipid indicators, and carotid intima media thickness in obese children and adolescents. Methods: A study group consisted of 110 obese children (11.5 \pm 2.9 years) and 38 healthy children (13.4 \pm 2.6 years). Obesity was defined using International Obesity Task Force criteria. In each patient anthropometric measurements, thyroid-stimulating hormone, free thyroxine, a lipid profile were evaluated. Carotid intima-media thickness was measured in 74 obese children and 28 lean children. The resulting data were used to calculate indicators of atherogenesis: total cholesterol to HDL cholesterol ratio; triglycerides to HDL cholesterol ratio and LDL cholesterol to HDL cholesterol ratio. Results: Obese children had higher mean serum thyroid-stimulating hormone levels compared to their lean peers and an adverse atherogenic lipid profile. Serum free thyroxine concentrations were comparable between the groups. Serum thyroid-stimulating hormone values correlated with total cholesterol to HDL cholesterol ratio; triglycerides to HDL cholesterol ratio, LDL cholesterol to HDL cholesterol ratio, and intima-media thickness. In a multivariate regression analysis, thyroid-stimulating hormone weakly correlated only with intima-media thickness after adjustment for age, gender and Body Mass Index $(\beta=0.249, p=0.04)$. This relationship weakened after considering a lipid profile $(\beta=0.242, p=0.058)$. No relationship was found for free thyroxine. Conclusion: Serum level of thyroid-stimulating hormone in obese children did not seem to impact atherogenic lipid indicators and carotid intima-media thickness. Therefore, an adverse lipid profile should still be considered the main risk factor for development of cardiovascular diseases in obese children.
\end{abstract}

\section{Introduction}

An increase in the number of overweight and obese children and adolescents over the past 30 years has led to higher incidence of metabolic and hemodynamic disturbances. This is a serious global health problem as cardiovascular diseases (CVD) are the main causes of morbidity and mortality in the world. Fat mass accumulation also leads to a mild thyroid dysfunction. Thyroid-stimulating hormone (TSH) at the upper limit of normal range or slightly elevated with a normal level of serum free thyroxine (fT4) and normal or moderately increased free triiodothyronine (fT3) is a relatively frequent finding in obese children and adolescents $^{(1)}$. According to the study by Ghergherehchi and Hazhir(2), the prevalence of subclinical hypothyroidism $(\mathrm{SCH})$ in children with obesity was significantly higher 
compared to non-obese children (14.7\% vs. $6.8 \%)$. It is believed that changes in TSH are a result of the adaptation process to excess of fat tissue and normalized after weight $\operatorname{loss}^{(1)}$.

In literature, there are a lot of studies in adult population investigating the relationship between subclinical hypothyroidism $(\mathrm{SCH})$ and higher risk of cardiovascular diseases but their results are inconsistent ${ }^{(3,4)}$. Some studies showed association of $\mathrm{SCH}$ with impaired diastolic left ventricular function, reduced systolic function during exercise and also increased peripheral vascular resistance, arterial stiffness, and endothelial dysfunction ${ }^{(4,5)}$. Patients with $\mathrm{SCH}$ had higher prevalence of aortic atherosclerosis and myocardial infarction ${ }^{(6)}$, increased thickness of carotid intima-media wall ${ }^{(7-9)}$ and impaired flow-dependent vasodilatation of brachial artery ${ }^{(10)}$. The negative impact of an adverse lipid profile and changes of glucose homeostasis on an endothelium structure and function is augmented by concurrent $\mathrm{SCH}^{(9,11-13)}$.

Given the cited data, the question arises to what extent an elevated serum TSH level augments the adverse impact of an altered lipid status on atherosclerosis process in obese children and adolescents. The number of studies concerning this topic is scarce ${ }^{(14)}$. In our previous study, we found that a serum TSH level correlated with total cholesterol, LDL cholesterol and triglycerides, even after adjustment for BMI or SDS BMI, but not with HDL cholesterol, fasting glucose and insulin resistance index HOMA (Homeostasis Model Assessment) ${ }^{(15)}$. Using data from the same group of obese children and adolescents now we investigate the relationship between serum TSH levels and atherogenic lipid indicators and endothelial remodeling by examining carotid intima-media thickness (IMT). The measurement of IMT by ultrasound is an important marker of an early stage of atherosclerosis, correlates well with cardiovascular risk factors and predicts the occurrence of myocardial infarction and stroke ${ }^{(16)}$.

\section{Material and methods}

A retrospective analysis was carried out on the basis of the medical history of 148 children, aged 5-18 years, hospitalized at the Department of Pediatrics and Endocrinology of the Medical University of Warsaw. All patients had a negative family history of thyroid disease and did not take any medication. The study group consisted of 110 children (48 girls, 62 boys, mean age $11.5 \pm 2.9$ years) found to be obese according to Body Mass Index (BMI) cut-off points for age and gender included in the International Obesity Task Force (IOTF) criteria ${ }^{(17)}$. Patients with secondary causes of obesity and systemic inflammatory diseases were excluded. The control group consisted of 38 healthy individuals (21 girls, 17 boys, mean age $13.4 \pm 2.6$ years) with normal somatic parameters. The project received approval of the Ethical Committee at the Medical University of Warsaw.

In each patient anthropometric measurements, i.e. body height $(\mathrm{cm})$, body weight $(\mathrm{kg})$, waist circumference and

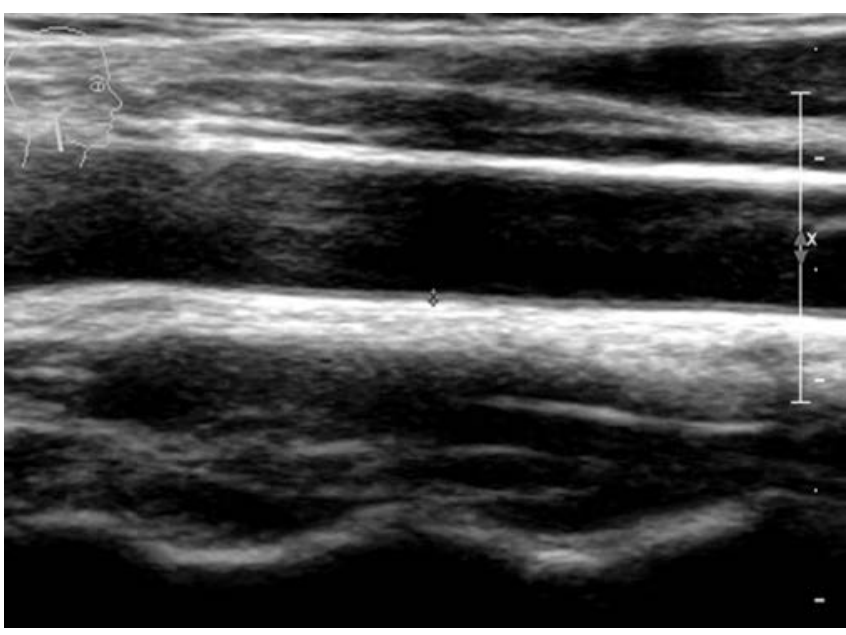

Fig. 1. Measurement of intima-media thickness (IMT) at the far wall of a common carotid artery about $1 \mathrm{~cm}$ from the bifurcation

hip circumference $(\mathrm{cm})$, thickness of 2 skinfolds $(\mathrm{mm})$ were analyzed. Based on these measurements, BMI (Body Mass Index), waist to hip ratio (WHR), waist to height ratio (WHtR) were calculated. Body fat percentage (\%FAT) was calculated using the Slaughter equations ${ }^{(18)}$. Cole's least mean square method was used to calculate standard deviation score of BMI (SDS BMI) expressing degree of obesity $^{(19)}$.

We also analyzed a lipid profile and thyroid function parameters. Serum thyroid-stimulating hormone (TSH, $\mu \mathrm{IU} /$ $\mathrm{ml}$ ) and free thyroxine (fT4, ng/dl) levels were measured by a microparticle immunoenzymatic assay (MEIA) using AXYM analyzer. In 5 patients with serum TSH levels $>4 \mu \mathrm{IU} / \mathrm{ml}$ anti-thyroid peroxidase (TPO-Ab) antibodies and anti-thyroglobulin (TG-Ab) antibodies were evaluated. A fasting lipid profile including total cholesterol (TC, mg/dl), triglycerides (TG, mg/dl) and high-density lipoprotein cholesterol (HDL-C, mg/dl) was assessed using commercially available kits. Low-density lipoprotein cholesterol (LDL-C, $\mathrm{mg} / \mathrm{dl}$ ) was calculated using the Friedewald formula (LDL-C $=\mathrm{TC}-\mathrm{TG} / 5+\mathrm{HDL}-\mathrm{C})$. The resulting data were used to calculate TC/HDL-C, TG/HDL-C, LDL-C/HDL-C ratios. Values of a lipid profile were interpreted according to the 2007 American Heart Association (AHA) recommendations $^{(20)}$. Normal values of TC/HDL-C ratio were $<5$, TG/ HDL-C $<3$, LDL-C/HDL-C $<3^{(21,22)}$.

Each obese child's blood pressure was measured at the right arm after a 10-minute rest in supine position using sphygmomanometer, and the average of three measurements was taken for analysis. The cuff size was based on the length and circumference of the upper arm and was chosen individually.

In 74 obese children and 28 children from the control group, thickness of carotid intima-media (IMT, mm) was evaluated at the Department of Pediatric Radiology. At the far wall of common carotid artery about $1 \mathrm{~cm}$ from the bifurcation, the distance between lumen-intima and media- 


\begin{tabular}{|c|c|c|c|c|}
\hline \multirow{2}{*}{ Variable } & \multirow{2}{*}{$\begin{array}{l}\text { Non-obese children } \\
\qquad(n=38)\end{array}$} & \multicolumn{3}{|c|}{ Obese children } \\
\hline & & $\begin{array}{c}\text { Total } \\
(n=110)\end{array}$ & $\begin{array}{c}\mathrm{TSH} \leq 4 \mu \mathrm{IU} / \mathrm{ml} \\
(n=104)\end{array}$ & $\begin{array}{c}\mathrm{TSH}>4 \mu \mathrm{lU} / \mathrm{ml} \\
(n=5)\end{array}$ \\
\hline TC (mg/dl) & $156.77 \pm 23.85$ & $177.47 \pm 29.52^{* * *}$ & $176.4 \pm 29.18$ & $196.0 \pm 31.79$ \\
\hline HDL-C (mg/dl) & $54(33-92)$ & $42(25-92)^{* * * *}$ & $42(25-92)$ & $49.5(30-58)$ \\
\hline LDL-C (mg/dl) & $84.26 \pm 25.64$ & $106.31 \pm 27.19^{* * *}$ & $105.58 \pm 27.01$ & $119.0 \pm 29.66$ \\
\hline TG (mg/dl) & $73(23-167)$ & $124(39-458)^{* * * *}$ & $123(39-458)$ & $162.5(106-219)$ \\
\hline TG/HDL-C & $1.29(0.33-4.28)$ & $2,99(0.53-14.31)^{* * *}$ & $2.99(0.53-14.31)$ & $3.75(2.0-6,1)$ \\
\hline LDL C/HDL C & $1.56(0.09-3.03)$ & $2.47(0.7-6.76)^{* * *}$ & $2.44(0.7-6.76)$ & $2.64(1,71-5.0)$ \\
\hline TC/HDL-C & $2.94(1.36-4.87)$ & $4.16(2.0-10.32)^{* * *}$ & $4.16(2.0-10.32)$ & $4.29(3.29-7.23)$ \\
\hline IMT & $0.58(0.25-0.73)$ & $0.6(0.22-1.4)$ & $0.6(0.22-1.4)$ & $0.65(0.5-0.7)$ \\
\hline \multicolumn{5}{|c|}{$\begin{array}{l}\text { Data are presented as mean } \pm \text { standard deviation (SD) or median with minimum and maximum values as appropriate } \\
\text { TSH - thyroid stimulating hormone; } \\
\text { TC - total cholesterol; } \\
\text { HDL-C - high-density lipoprotein cholesterol; } \\
\text { LDL-C - low-density lipoprotein cholesterol; } \\
\text { TG - triglycerides; } \\
\text { TC/HDL-C - total cholesterol to HDL cholesterol ratio; } \\
\text { TG/HDL-C - triglycerides to HDL cholesterol ratio; } \\
\text { LDL-C/HDL-C - LDL cholesterol to HDL cholesterol ratio; } \\
\text { IMT - intima media thickness } \\
* * * 0<001 \text {, } \\
{ }^{* *} p<0,01 \text {, } \\
* p<0,05 \text { (comparison: non obese children } v \text { s. obese children) }\end{array}$} \\
\hline
\end{tabular}

Tab. 1. The comparison of lipid profiles, atherogenic lipid indicates and carotid intima-media thickness in the non-obese children and the obese children divided according to the value of TSH level

adventica interferences was measured using 12-15 $\mathrm{MHz}$ ultrasound high resolution linear vascular probe on ATL 3000 HDL (Bothell, Washington DC, Fig. 1). The average of three measurements on both sides was considered the final carotid IMT value.

All statistical calculations were performed using SPPS 19 software. Data are expressed as mean and standard deviation (SD) or median with minimum and maximum values. For comparison of anthropometric and biochemical measurements between the obese and the control (lean) groups, the T-test was used for parameters in normal distribution, in the case of non-normal distribution the Mann-Whitney test was used. The correlations between the measured variables were calculated using the Spearman coefficient. For better assessment of the relationship between TSH and IMT, multivariate linear regression models were used. A $p$ value $<0.05$ was considered as indicator of statistical significance.

\section{Results}

The mean BMI of the obese children was $29.36 \pm 4.9 \mathrm{~kg} / \mathrm{m}^{2}$, the mean SDS BMI was $2.78 \pm 0.49$. All the children had high body fat percentage, averaging $33.91 \pm 4.71 \%$. The mean waist circumference was $89.94 \pm 12.31 \mathrm{~cm}$. The mean BMI of the lean children was $18.86 \pm 2.79 \mathrm{~kg} / \mathrm{m}^{2}$, SDS BMI $-0.03 \pm 0.89$. Mean heights of children from both groups were comparable $(152.76 \pm 16,62 \mathrm{~cm}$ in the obese group, $157.47 \pm 12.94 \mathrm{~cm}$ in the lean group).

In obese children, serum TSH levels were between 0.44-4.9 $\mu \mathrm{IU} / \mathrm{ml}$. Mean values of serum TSH were significantly higher compared to those in their lean peers $(2.14 \pm 0.97 \mu \mathrm{IU} / \mathrm{ml}$ vs. $1.47 \pm 0.63 \mu \mathrm{IU} / \mathrm{ml}, p=<0.001)$. TSH levels $4 \mu \mathrm{IU} / \mathrm{ml}$ were found only in 5 patients. Serum fT4 was within normal range and did not differ when compared to the control group. Obese children had a significantly adverse lipid profile. Elevated serum total cholesterol level (TC $\geq 200 \mathrm{mg} / \mathrm{dl}$ ) and LDL cholesterol level (LDL-C $\geq 130 \mathrm{mg} / \mathrm{dl}$ ) were found in $24(21.8 \%)$ and $17(15.5 \%)$ obese children, respectively. Increased values of triglycerides $(\geq 110 \mathrm{mg} / \mathrm{dl})$ were detected in $73(66.4 \%)$ patients. Forty $(36.4 \%)$ obese children had low $(<40 \mathrm{mg} / \mathrm{dl})$ levels of HDL-C. Increased values of TC/ HDL-C $\geq 5$, TG/HDL-C $\geq 3$, LDL-C/HDL-C $\geq 3$ were found in $22(20 \%), 55(50 \%), 25(22.7 \%)$ obese children, respectively. After dividing the group of obese children according to TSH level we observed higher mean or median values of TC, LDL-C, TG and atherogenic indicators in children with serum TSH $>4 \mu \mathrm{IU} / \mathrm{ml}$, but because of the low number of patients, a statistical analysis cannot be performed. Likewise, these groups of children had the highest median carotid IMT value (Tab. 1, Fig. 2). These two subgroups of obese children did not differ with respect to BMI, SDS BMI, waist circumference and \%FAT. The characteristics of a lipid status and IMT of obese children and control groups are presented in Table 1. Median systolic blood 
pressure (SBP) in obese children was $114 \mathrm{mmHg}$, median diastolic blood pressure (DBP) was $70 \mathrm{mmHg}$ and did not differ between the subgroups with higher and lower serum TSH levels.

In Spearman correlation serum TSH values correlated with TC/HDL-C $(r=0.286, p<0.001)$, TG/HDL-C $(r=$ $0.236, p=0.004)$, LDL-C/HDL-C $(r=0.281, p=0.001)$, and carotid IMT $(r=0.290, p=0.003)$, but not with SBP and DBP. In multivariate linear regression analysis, after adjustment for age, gender and SDS BMI, TSH correlated weakly only with IMT. Furthermore, this relationship was weaker after considering a lipid profile (Tab. 2). No relationship was found for fT4.

\section{Discussion}

It is well known that atherosclerosis can start in childhood and is mainly caused by accumulation of fat mass and obesity-related development of metabolic and hemodynamic disturbances such as dyslipidemia, insulin resistance, impaired glucose tolerance or hypertension. Obesity also leads to slightly elevated serum TSH levels accompanied by a normal level of free thyroxine (fT4), suggesting subclinical hypothyroidism ( $\mathrm{SCH}$ ). Recently, the association between SCH and a higher risk of atherosclerotic diseases has been the subject of many studies in adult population. Their results are not clear, but some meta-analysis has confirmed such a link ${ }^{(23)}$. Also, considering multidirectional action of thyroid hormone, the question arises what role elevated TSH plays in the onset of atherosclerosis in obese children. We analyzed the measurements of carotid intima media thickness as a useful tool in evaluation of subclinical atherogenesis.

The meta-analysis by Gao et al. ${ }^{(12)}$ based on 8 observational studies including 3602 adult patients confirmed the association between SCH and increased IMT, which may be a result of elevated $\mathrm{TSH}$, dyslipidemia and hypertension. In other studies $^{(8,9)}$ authors point out that this relationship is independent from traditional risk factors. Data regarding this problem in pediatric population are limited. Isik-Balci et al. ${ }^{(24)}$ and Ünal et al. ${ }^{(13)}$ found higher thickness of carotid IMT in children with $\mathrm{SCH}$ than in control groups. In a study including 81 overweight and obese children, Schiel et al. ${ }^{(25)}$ showed that IMT correlated with selected anthropometric parameters describing obesity, blood pressure and also with TSH. In another study, in a group of 58 obese children with nonalcoholic fatty liver disease (NASH), Sert et al. ${ }^{(26)}$ demonstrated a negative impact of subclinical hypothyroidism on cardiovascular risk factors. Twenty-five individuals with $\mathrm{TSH}>4 \mu \mathrm{IU} / \mathrm{ml}$ had higher thickness of carotid IMT, higher left ventricular mass (LVM) and also a more unfavorable lipid profile and glucose metabolism parameters compared to obese peers without diagnosed $\mathrm{SCH}$. In a multivariate regression analysis $\mathrm{TSH}$ correlated positively with IMT, after adjustment for age, gender, BMI, blood pressure, a lipid profile, fasting glucose, fasting insulin and HOMA. Another study not only confirmed impaired cardiac function as a reduced diastolic function and a lon- gitudinal systolic function assessed by Doppler Echocardiography ${ }^{(14)}$, but also showed alteration of hemorheological parameters in children with $\mathrm{SCH}^{(24)}$. The study by Özer et al. (27), including 260 obese children, found that an elevated TSH level is a risk factor for a metabolic syndrome.

In our study, serum TSH concentration also correlated with IMT after adjustment for age, gender and SDS BMI, but this relationship was attenuated after considering a lipid profile. The results of our analysis suggest that changes of a lipid profile found in obese children had a greater impact on thickness of carotid intima-media and perhaps TSH contributes to early atherosclerosis vascular changes through an action on lipid metabolism. Akkoca's et al. ${ }^{(7)}$ reached similar conclusions in their study. In 60 nonobese adults divided into three equal groups with a normal thyroid function, subclinical hypothyroidism and clinical hypothyroidism, it was found that increased thickness of a carotid IMT wall resulted from an adverse lipid status.

Thyroid hormones regulate synthesis, metabolism and mobilization of lipids. They increase cholesterol synthesis in the liver and expression of a cell surface LDL-C receptor in the liver and other tissues and decrease intestinal cholesterol absorption. Thyroid hormones increase cholesterol ester transfer protein (CETP) concentration and increase the activity of hepatic lipase and lipoprotein lipase, and thus impact HDL-C and triglyceride concentration ${ }^{(11)}$. The effect of subclinical hypothyroidism on a serum lipid profile is not quite clear. The presence of $\mathrm{TSH}$ receptor in hepatocytes potentially explains the role of thyrotropin in the formation of hypercholesterolemia ${ }^{(28)}$. Some studies in adult patients have reported a relationship between subclinical hypothyroidism and an adverse lipid status ${ }^{(9,11)}$. Moreover, the HUNT study including a group of 30656 patients demonstrated that increased serum TSH levels, but still within the normal range, positively correlated with total cholesterol, LDL cholesterol and triglycerides and negatively correlated with HDL-C ${ }^{(29)}$. The results of these studies are supported by research in obese children conducted by Aeberli et al. ${ }^{(30)}$, Pacifico et al. ${ }^{(31)}$ and Shalitin

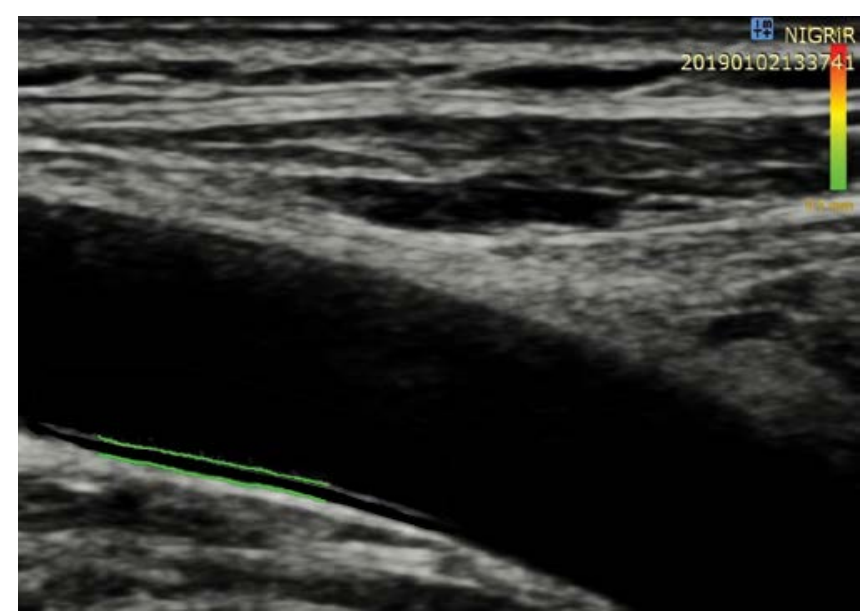

Fig. 2. Increased thickness of carotid intima-media in a 12 years old girl from the obese group 


\begin{tabular}{|c|c|c|c|c|}
\hline $\begin{array}{l}\text { Independent } \\
\text { variables }\end{array}$ & B & SE & $p$-value & $\mathbf{9 5} \% \mathrm{Cl}$ \\
\hline MODEL 1 & & & & \\
\hline Age (years) & 0.008 & 0.007 & 0.258 & $-0.006-0.021$ \\
\hline $\begin{array}{l}\text { Sex }(\text { male }=1 / \\
\text { female }=2)\end{array}$ & -0.052 & 0.036 & 0.153 & $-0.124-0.019$ \\
\hline SDS BMI & $0, .047$ & 0.041 & 0.259 & $-0.034-0.127$ \\
\hline $\mathrm{TSH}(\mu \mathrm{lU} / \mathrm{ml})$ & 0.041 & 0.020 & 0.041 & $0.003-0.080$ \\
\hline MODEL 2 & & & & \\
\hline Age (years) & 0.008 & 0.007 & 0.282 & $-0.006-0.022$ \\
\hline $\begin{array}{l}\text { Sex }(\text { male }=1 / \\
\text { female }=2)\end{array}$ & -0.052 & 0.038 & 0.0170 & $-0.126-0.022$ \\
\hline SDS BMI & 0.049 & 0.043 & 0.255 & $-0.035-0.134$ \\
\hline TC (mg/dl) & 0.000 & 0.002 & 0.844 & $-0.004-0.004$ \\
\hline LDL-C (mg/dl) & 0.000 & 0.002 & 0.838 & $-0.005-0.004$ \\
\hline TG (mg/dl) & 0.000 & 0.000 & 0.878 & $-0.001-0.001$ \\
\hline $\mathrm{TSH}(\mu \mathrm{lU} / \mathrm{ml})$ & 0.040 & 0.021 & 0.058 & $-0.001-0.081$ \\
\hline
\end{tabular}

SDS BMI - standard deviation score of Body Mass Index;

TC - total cholesterol;

HDL-C - high-density lipoprotein cholesterol;

LDL-C - low-density lipoprotein cholesterol;

TG - triglycerides;

$\mathrm{TSH}$ - thyroid stimulating hormone;

B - non-standardized coefficient;

SE - standard error;

$\mathrm{Cl}$ - confidence interval

Tab. 2. Multivariate regression analysis of intima-media thickness (dependent variable)

et al. ${ }^{(32)}$. In our study, obese children with TSH $>4$ uIU/ $\mathrm{ml}$, besides increased mean/median levels of serum lipids, demonstrated elevated values of an atherogenic lipid indicator, but this group is too small to establish any statistical significance. What is more, as in our previous study ${ }^{(15)}$, we found a relationship between TSH and triglicerydes, total cholesterol and LDL cholesterol, however, in the present study we did not find any association between TSH and atherogenic lipid indicators, after adjustment for age, gender and SDS BMI. This raises doubts about the role of TSH in pathogenesis of atherosclerosis in obese children. In literature only a few studies described significant differ-

\section{References}

1. Sanyal D, Raychaudhuri M: Hypothyroidism and obesity: an intriguing link. Indian J Endocrinol Metab 2016; 20: 554-557.

2. Ghergherehchi R, Hazhir N: Thyroid hormonal status among children with obesity. Ther Adv Endocrinol Metab 2015; 6: 51-55.

3. Lioudaki E, Mavroeidi NG, Mikhailidis DP, Ganotakis ES: Subclinical hypothyroidism and vascular risk: an update. Hormones (Athens) 2013; 12: 495-506.

4. Floriani C, Gencer B, Collet TH, Rodondi N: Subclinical thyroid dysfunction and cardiovascular diseases: 2016 update. Eur Heart J 2018; 39: 503-507.

5. Pearce SH, Brabant G, Duntas LH, Monzani F, Peeters RP, Razvi S et al.: ETA guideline: Management of subclinical hypothyroidism. Eur Thyroid J 2013; 2: 215-228.

6. Hak AE, Pols HA, Vissel TJ, Drexhage HA, Hofman A, Witteman JC: Subclinical hypothyroidism is an independent risk factor for atherosclerosis and myocardial infarction in elderly women: The Rotterdam study. Ann Intern Med 2000; 132: 270-278. ences in TC/HDL-C and LDL-C/HDL-C ratios in patients with $\mathrm{SCH}$ compared to control groups ${ }^{(9,13)}$.

Our findings did not indicate an evident link between serum TSH levels in obese children and cardiovascular risk factors. It seems that higher serum TSH levels related to obesity may participate in changes of thickness of intimamedia wall through an adverse lipid profile. Because of the small size of the group, especially of the subclinical hypothyroidism subgroup, which is a limitation of our study, further investigation is needed. Determining whether isolated hiperthyreotropinemia is an additional cardiovascular risk factor is essential for prevention of atherosclerosis. This is particularly important for pediatricians in the context of the beneficial role of L-thyroxine (LT4) replacement therapy in reducing cardiovascular risk factors. According to European Thyroid Association (2014), there is insufficient evidence to recommend L-thyroxine treatment of children with TSH $<10 \mathrm{mU} / \mathrm{L}$ and normal TT4/fT4 concentration and decisions in the case of those children should be taken individually ${ }^{(33)}$. Some studies have showed serum TSH normalization and insulin sensitivity improvement after weight $\operatorname{loss}^{(30,34)}$. A retrospective study by Matusik et al. ${ }^{(35)}$ found that LT4 treatment combined with a diet and physical intervention in obese children with SCH did not improve weight loss compared to children without LT4 therapy.

\section{Conclusion}

Obese children and adolescents are predisposed to higher levels of serum TSH in comparison to their normal-weight peers. However, increased serum TSH does not seem to impact atherogenic lipid indicators and carotid IMT. Therefore, an adverse lipid profile should still be considered the main risk factor for development of cardiovascular disease in obese children.

\section{Conflict of interest}

The authors declare no conflicts of interest in relation to this article.
7. Akkoca AN, Özdemir ZT, Özler GS, Karabulut L: The evaluation of carotid intima thickness in clinical and subclinical hypothyroidism and effects of thyroid hormone treatment. Am J Clin Exp Med 2014; 2: 59-63.

8. Peixoto de Miranda ÉJ, Bittencourt MS, Pereira AC, Goulart AC, Santos IS. Lotufo PA et al.: Subclinical hypothyroidism is associated with higher carotid intima-media thickness in cross-sectional analysis of the Brazilian Longitudinal Study of Adult Health (ELSA-Brasil). Nutr Metab Cardiovasc Dis 2016; 26: 915-921.

9. Valentina VN, Marijan B, Chedo D, Branka K: Subclinical hypothyroidism and risk to carotid atherosclerosis. Arq Bras Endocrinol Metabol 2011; 55: 475-480.

10. Razvi S, Ingoe L, Keeka G, Oates C, McMillan C, Weaver JU: The beneficial effect of $\mathrm{L}$ thyroxine on cardiovascular risk factors, endothelial function, and quality of life in subclinical hypothyroidism: randomized, crossover trial. J Clin Endocrinol Metab 2007; 92: 1715-1723.

11. Pearce EN: Update in lipid alterations in subclinical hypothyroidism. J Clin Endocrinol Metab 2012; 97: 326-333. 
12. Gao N, Zhang W, Zhang YZ, Yang Q, Chen SH: Carotid intima-media thickness in patients with subclinical hypothyroidism: a meta-analysis. Atherosclerosis 2013; 227: 18-25.

13. Ünal E, Akın A, Ylldırım R, Demir V, Yildiz I, Haspolat YK: Association of subclinical hypothyroidism with dyslipidemia and increased carotid intima-media thickness in children. J Clin Res Pediatr Endocrinol 2016; 9: 144-149.

14. Brienza C, Grandone A, Di Salvo G, Corona AM, Di Sessa A, Pascotto C et al.: Subclinical hypothyroidism and myocardial function in obese children. Nutr Metab Cardiovasc Dis 2013; 23: 898-902.

15. Rumińska M, Witkowska-Sędek E, Majcher A, Pyrżak B: Thyroid function in obese children and adolescents and its association with anthropometric and metabolic parameters. Adv Exp Med Biol 2016; 912: 33-41.

16. Lorenz MW, Markus HS, Bots ML, Rosvall M, Sitzer M: Prediction of clinical cardiovascular events with carotid intima-media thickness: A systematic review and meta-analysis. Circulation 2007; 115: 459-467.

17. Cole TJ, Bellizzi MC, Flegal KM, Dietz WH: Establishing a standard definition for child overweight and obesity worldwide: international survey. BMJ 2000; 320: 1240-1243.

18. Slaughter MH, Lohman TG, Christ CB, Boileau RA: Skinfold equations for estimation of body fitness in children and youth. Hum Biol 1988; 60: 709-723.

19. Cole TJ: The LMS method for constructing normalized growth standard. Eur J Clin Nutr 1990; 44: 45-60.

20. Hayman LL, Meininger JC, Daniels SR, McCrindle BW, Helden L, Ross J et al.: Primary prevention of cardiovascular disease in nursing practice: focus on children and youth: A scientific statement from the American Heart Association Committee on Atherosclerosis, Hypertension, and Obesity in Youth of the Council on Cardiovascular Disease in the Young, Council on Cardiovascular Nursing, Council on Epidemiology and Prevention, and Council on Nutrition, Physical Activity, and Metabolism. Circulation 2007; 116: 344-357.

21. Millán J, Pintó X, Muñoz A, Zúñiga M, Rubiés-Prat J, Pallardo LF et al.: Lipoprotein ratios: physiological significance and clinical usefulness in cardiovascular prevention. Vasc Health Risk Manag 2009; 5: 757-765.

22. Olson K, Hendricks B, Murdock DK: The triglyceride to HDL ratio and its relationship to insulin resistance in pre- and postpubertal children: observation from the Wausau SCHOOL Project. Cholesterol 2012;2012:794252.

23. Ochs N, Auer R, Bauer DC, Nanchen D, Gussekloo J, Cornuz J et al.: Meta-analysis: subclinical thyroid dysfunction and the risk for coronary heart disease and mortality. Ann Intern Med 2008; 148: 832-845.

24. Isik-Balci Y, Agladioglu S, Agladioglu K, Kilic-Toprak E, Kilic-Erkek O, Ozhan B et al.: Impaired hemorheological parameters and increased carotid intima-media thickness in children with subclinical hypothyroidism. Horm Res Paediatr 2016; 85: 250-256.

25. Schiel R, Beltschikow W, Radón S, Kramer G, Perenthaler T, Stein G: Increased carotid intima-media thickness and associations with cardiovascular risk factors in obese and overweight children and adolescents. Eur J Med Res 2007; 12: 503-508.

26. Sert A, Pirgon O, Aypar E, Yilmaz H, Odabas D: Subclinical hypothyroidism as a risk factor for the development of cardiovascular disease in obese adolescents with nonalcoholic fatty liver disease. Pediatr Cardiol 2013; 34: 1166-1174.

27. Özer S, Bütün I, Sönmezgöz E, Yılmaz R, Demir O: Relationships among thyroid hormones and obesity severity, metabolic syndrome and its components in Turkish children with obesity. Nutr Hosp 2015; 32: 645-651.

28. Zhang W, Tian L, Han Y, Ma H, Wang LC, Guo J et al.: Presence of thyrotropin receptor in hepatocytes: not a case of illegitimate transcription. J Cell Mol Med 2009; 13: 4636-4642.

29. Asvold BO, Vatten LJ, Nilsen TI, Bjøro T: The association between TSH within the reference range and serum lipid concentrations in a population-based study. The HUNT Study. Eur J Endocrinol 2007; 156: $181-186$.

30. Aeberli I, Jung A, Murer SB, Wildhaber J, Wildhaber-Brooks J, Knöpi BH et al.: During rapid weight loss in obese children, reductions in TSH predict improvements in insulin sensitivity independent of changes in body weight or fat. J Clin Endocrinol Metab 2010; 95: 5412-5418.

31. Pacifico L, Anania C, Ferraro F, Andreoli GM, Chiesa C: Thyroid function in childhood obesity and metabolic comorbidity. Clin Chim Acta 2012; 413: 396-405.

32. Shalitin S, Yackobovitch-Gavan M, Phillip M: Prevalence of thyroid dysfunction in obese children and adolescents before and after weight reduction and its relation to other metabolic parameters. Horm Res 2009; 71: 155-161.

33. Lazarus J, Brown RS, Daumerie C, Hubalewska-Dydejczyk A, Negro R, Vaidya B: 2014 European thyroid association guidelines for the management of subclinical hypothyroidism in pregnancy and in children. Eur Thyroid J 2014; 3: 76-94.

34. Wolters B, Lass N, Reinehr T: TSH and free triiodothyronine concentrations are associated with weight loss in a life style intervention and weight regain afterwards in obese children. Eur J Endocrinol 2013; 168: 323-329.

35. Matusik P, Gawlik A, Januszek-Trzciakowska A, Malecka-Tendera E: Isolated subclinical hyperthyrotropinemia in obese children: does levothyroxine (LT4) improve weight reduction during combined behavioral therapy? Int J Endocrinol 2015; 2015: 792509. 